\title{
Management of trichobezoar: case report and literature review
}

\author{
R. R. Gorter • C. M. F. Kneepkens • \\ E. C. J. L. Mattens • D. C. Aronson • \\ H. A. Heij
}

Accepted: 2 February 2010/Published online: 6 March 2010

(c) The Author(s) 2010. This article is published with open access at Springerlink.com

\begin{abstract}
Trichobezoars (hair ball) are usually located in the stomach, but may extend through the pylorus into the duodenum and small bowel (Rapunzel syndrome). They are almost always associated with trichotillomania and trichophagia or other psychiatric disorders. In the literature several treatment options are proposed, including removal by conventional laparotomy, laparoscopy and endoscopy. We present our experience with four patients and provide a review of the recent literature. According to our experience and in line with the published results, conventional laparotomy is still the treatment of choice. In addition, psychiatric consultation is necessary to prevent relapses.
\end{abstract}

Keywords Trichobezoar - Trichotillomania ·

Rapunzel syndrome · Therapy

R. R. Gorter - E. C. J. L. Mattens - D. C. Aronson ·

H. A. Heij $(\square)$

Pediatric Surgical Center of Amsterdam,

Emma Children's Hospital AMC and VU University

Medical Center, P.O. Box 22660,

1100 DD Amsterdam, The Netherlands

e-mail: kinderchir@vumc.nl

C. M. F. Kneepkens

Department of Pediatric Gastroenterology,

VU University Medical Center,

Amsterdam, The Netherlands

Present Address:

D. C. Aronson

Department (Division) of Pediatric Surgery,

Radboud University Nijmegen Medical Center,

Nijmegen, The Netherlands

\section{Introduction}

Trichobezoar, a hair ball in the proximal gastrointestinal tract, is a rare condition almost exclusively seen in young females [1-5]. Human hair is resistant to digestion as well as peristalsis due to its smooth surface. Therefore it accumulates between the mucosal folds of the stomach. Over a period of time, continuous ingestion of hair leads to the impaction of hair together with mucus and food, causing the formation of a trichobezoar. In most cases the trichobezoar is confined within the stomach. In some cases, however, the trichobezoar extends through the pylorus into jejunum, ileum or even colon. This condition, called Rapunzel syndrome, was first described by Vaughan et al. in 1968 [6, 7]. In addition, incidentally, parts of the tail can break off and migrate to the small intestine, causing intestinal obstruction [8-10]. In the early stage, most trichobezoars may not be recognized due to their nonspecific presentation or even lack of symptoms in the early stages. One should be aware of a trichobezoar in young females with psychiatric comorbidity, as it is usually the result of the urge to pull out one's own hair (trichotillomania) and swallow it (trichophagia). Other psychiatric disorders, however, such as mental disorders, abuse, pica, obsessive compulsive disorder, depression and anorexia nervosa may also be associated with trichobezoar $[3,11,12]$. When not recognized, the trichobezoar continues to grow in size and weight due to the continued ingestion of hair. This increases the risk of severe complications, such as gastric mucosal erosion, ulceration and even perforation of the stomach or the small intestine. In addition, intussusception, obstructive jaundice, protein-losing enteropathy, pancreatitis and even death have been reported as complications of (unrecognized) trichobezoar in the literature [13-17].

Following the introduction of minimally invasive surgery and endoscopy with mechanical and laser 
fragmentation techniques, some authors have questioned the necessity of laparotomy for trichobezoar and consider these new techniques as to be preferred for trichobezoar removal [8, 18-23]. The aim of this study is to evaluate our experience and to select the most appropriate approach in light of these new developments, based on a thorough review of the current literature.

\section{Patients and methods}

Between 1990 and 2008, four patients have been treated for trichobezoar in our center. Their medical charts were reviewed with respect to symptoms, diagnostic procedures and treatment. In addition, all published case reports or studies of trichobezoar in children (age 0-18) were identified through a Medline search (January 1990 until January 2009), using 'trichobezoar' as the keyword. The abstracts were reviewed. Studies and case reports were eligible when they were written in or translated into English or Dutch, provided at least one case of trichobezoar in the specified age group, and mentioned treatment and postoperative course of the patients. We then obtained and analyzed the full papers. References cited by these papers were also reviewed for eligibility.

\section{Results}

Symptoms, diagnostic procedures and treatment of the four patients are outlined in Tables 1 and 2. All were females and between 9 and 15 years old. One patient (\#2) presented with signs of peritonitis and was found to have elevated blood and urine amylase. As a sealed perforation with reactive pancreatitis was suspected, she underwent urgent diagnostic laparoscopy without further visualization of the gastrointestinal tract. One patient (\#1) suffered from Rapunzel syndrome. The trichobezoar extended from the stomach through the pylorus into the jejunum (Figs. 1, 2). In case \#4, MRI preceded barium contrast studies due to the suspicion of a malignancy (Fig. 3). Gastroscopic removal with either mechanical or laser fragmentation was attempted in two patients, but failed and was followed by conventional laparotomy. All patients eventually proved to suffer from trichophagia and referred to a child psychiatrist or psychologist. No recurrences have been reported.

\section{Discussion}

Although rare, trichobezoar may present as an emergency that surgeons should be prepared to deal with.

We have reported our experience of four patients, who were eventually diagnosed with and treated for trichobezoar. This subject has recently attracted attention because of the debate about the application of minimally invasive techniques such as endoscopy and laparoscopy [8, 18-27]. The literature on trichobezoar in children almost exclusively deals with case reports. In total, 108 cases (Table 3) could be identified within our search limits, most of them females, as was the case for our four patients. As is demonstrated by our cases and the literature, trichobezoars are

Table 1 Cases: diagnostic features

\begin{tabular}{|c|c|c|c|c|}
\hline & \multicolumn{4}{|l|}{ Case number } \\
\hline & 1 & 2 & 3 & 4 \\
\hline Sex & Female & Female & Female & Female \\
\hline Age & 9 & 14 & 15 & 7 \\
\hline Chronic abdominal pain & No & Yes & Yes & No \\
\hline Vomiting & Yes & Yes & No & No \\
\hline Weight loss & Yes & No & Yes & No \\
\hline Alopecia & No & No & No & Yes \\
\hline Mass palpable & Yes & No & Yes & Yes \\
\hline Signs of peritonitis & No & Yes & No & No \\
\hline Psychiatric comorbidity & Mental disturbance & None & Trichophagia & Trichophagia \\
\hline Laboratory results & & $\begin{array}{l}\text { Elevated blood and } \\
\text { urine amylase }\end{array}$ & & Anemia \\
\hline Plain abdominal X-ray results & Shadow abdomen & Air-fluid levels & & \\
\hline Ultrasound results & & Free fluid & & Intraluminal mass \\
\hline Barium contrast study results & Intraluminal mass & & & Intraluminal mass \\
\hline MRI results & & & & Intraluminal mass \\
\hline Endoscopic results & Trichobezoar & & Trichobezoar & \\
\hline Diagnosis made before surgery & Yes & No & Yes & Yes \\
\hline
\end{tabular}


Table 2 Cases: treatment features

\begin{tabular}{lllll}
\hline & Case number & & & \\
\cline { 2 - 5 } & 1 & 2 & Stomach & Stomach \\
\hline Location & Rapunzel & Stomach & Endoscopy & Laparotomy \\
Treatment & Endoscopy & Laproscopy & No & Yes \\
Succesfull & No & No & Yes & Yes \\
Conventional laprotomy & Yes & Yes & Gastric ulcer & Gastric ulcer \\
Associated pathology & Intussusception & Reactive pancreatitis & No & No \\
Satellites in small intestine & No & Yes & $10 \times 25 \mathrm{~cm}$ & W \\
Size & $25 \times 15 \times 5 \mathrm{~cm}$ & $?$ & Wound infection & Wound infection \\
Postoperative complications & None & None & No & No \\
Recurrences? & No & No & Yes & Yes \\
Additional psychiatric consultation & Yes & Yes & &
\end{tabular}

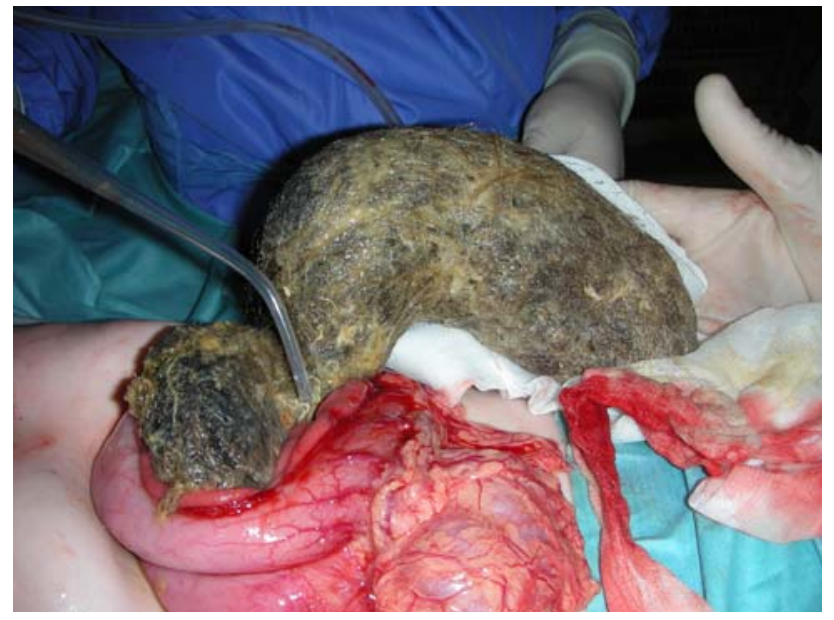

Fig. 1 Rapunzel syndrome (patient \#1)

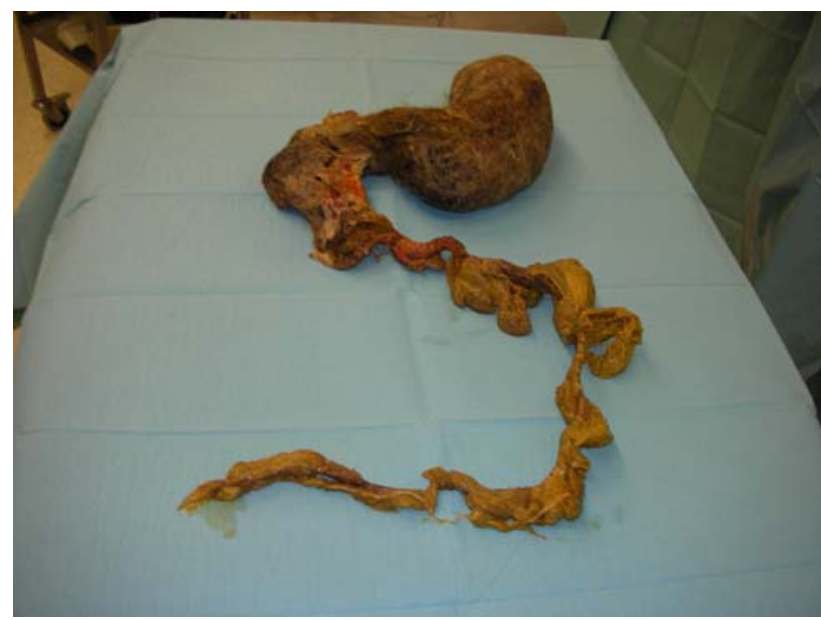

Fig. 2 Rapunzel syndrome: after removal: the cast of the stomach with the tail located in the jejunum (patient \#1)

often not recognized at the initial presentation and the diagnosis is often delayed. Masses in the epigastric region are usually interpreted as suspected for malignant

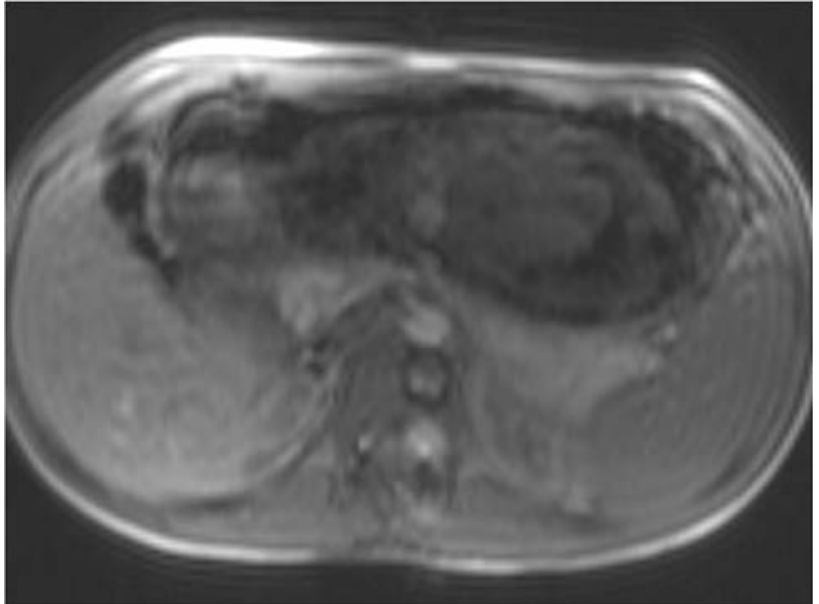

Fig. 3 MRI (transversal view) in case \#4: symptoms and signs (upper abdominal mass, confirmed with ultrasound) were interpreted as suggestive of a malignant process. MRI revealed the presence of an intraluminal mass in the stomach

processes, as is shown by case \#4, who immediately underwent MR-imaging. When not recognized, trichobezoars may result in severe complications (Table 3). All our cases suffered from trichobezoar-related complications. The most common complication is perforation of either the stomach or the intestine (Table 3). Two of our cases suffered from gastric ulcer. Due to the significant size of the trichobezoar in most cases, the blood supply to the mucosa of the stomach and part of the intestine is reduced, which may cause ulceration and eventually perforation. Of special interest are cases \#1 and \#2, who suffered from intussusception and reactive pancreatitis, respectively, both uncommon complications [16, 28, 29]. Trichobezoar should be considered as a differential diagnosis in young females who present with non-specific symptoms such as epigastric pain, fatigue, weight loss and epigastric mass.

The main focus of this paper is to evaluate our experience with the treatment of trichobezoar in light of the 
Table 3 Overview of the literature

\begin{tabular}{ll}
\hline & Number of cases \\
\hline Case reports & 98 \\
Number of cases & 108 \\
Complications & \\
Perforation (stomach/intestine) & 11 \\
Intussusception & 2 \\
Pancreatitis & 1 \\
Cholangitis & 1 \\
Other & 2 \\
Treatment & \\
Endoscopy & \\
$\quad$ Number of cases & 40 \\
Successful & $2(5 \%)$ \\
$\quad$ Number of complications & 0 \\
Laparoscopy & \\
Number of cases & 8 \\
Successful & $6(75 \%)$ \\
Number of complications & 0 \\
Laparotomy & $12(12 \%)$ \\
Number of cases &
\end{tabular}

recent literature. Although most of the 108 case reports we collected mention the treatment used, treatment strategy was never the main focus of the study. There is one exception: Koulas et al. [30] reported on the management of gastrointestinal bezoars in general. Due to lack of information on the ages of the patients, the types of bezoar and the actual treatment strategies, this study could not be included in the review. We consider that the optimal therapy combines minimal invasiveness with optimal efficacy. Medical treatment and enzymatic degradation, although attractive because of their noninvasiveness, have been reported as ineffective [31,32].

\section{Endoscopy}

Endoscopic removal, if effective, would be the most attractive alternative. The first report of successful endoscopic removal of a trichobezoar concerned a relatively small one, weighing only $55 \mathrm{~g}$ [33]. In two of our cases endoscopic removal was attempted, but was unsuccessful. Reports of successful endoscopic removal of trichobezoars are remarkably scarce, however; they are vastly outnumbered by case reports documenting unsuccessful attempts of endoscopic removal with or without fragmentation in children $[8,18,19,26,27,34,35]$. We were able to identify 40 cases in which endoscopic removal had been tried of which only two were successful $(5 \%)[18,19]$. In one of these, a trichobezoar was successfully removed as a whole from the distal esophagus [18]. In a series of 15 patients with bezoars, a 15-year-old girl underwent fragmentation of a large trichobezoar by means of a modified needle-knife and monopolar coagulation current [19]. In most case reports, however, fragmentation was considered impossible because of size, density and hardness, and endoscopy was not considered a viable therapeutic option $[8,26,27,34,35]$. Moreover, as the removal of all fragments requires manifold repeated introduction of the endoscope, pressure ulceration, esophagitis and even esophageal perforation may ensue [20, 36]. Additionally, fragments of a large trichobezoar might migrate after fragmentation or repeated manipulation through the pylorus, causing intestinal obstruction further distally [37]. Careful examination of the intestine for satellites, however, cannot be done with endoscopy, let alone that removal of those fragments is possible. Although not a therapeutic option, however, as a diagnostic modality endoscopy may prove to be extremely valuable in patients in whom the nature of the gastric mass is unclear. It enables the differentiation between trichobezoars and foreign bodies that can be fragmented and removed endoscopically [27, 38].

\section{Laparoscopy}

In one of our cases laparoscopy was the initial procedure, but it was converted into laparotomy when a large intragastric mass was encountered. In our center we consider laparoscopy inferior to laparotomy for the treatment of trichobezoar. Nirasawa et al. [21] were the first to report on laparoscopic removal of a trichobezoar. Since then only six other reports of attempted laparoscopic removal were published (Table 4) [8, 20, 22-25]. The lack of reports on endoscopic treatment might partly be explained by the rarity of trichobezoar but it could also indicate that laparoscopy is not an attractive treatment modality for trichobezoar. Of the six case reports, two reported failure of removing the trichobezoar, caused by the size of the trichobezoar or by satellite trichobezoars in other locations of the gastrointestinal tract [24, 25]. In one study, endoscopic and laparoscopic approaches were combined; as endoscopic fragmentation of the bezoar was not possible, a laparoscopic approach was used for fragmentation of the trichobezoar, while endoscopy was used for removal of the fragments [20]. Successful laparoscopic removal, however, requires significantly longer operation time as compared to conventional laparotomy, mostly due to the complexity of the operation. Careful examination of the entire digestive system (intestine and stomach) is necessary in order to prevent secondary intestinal obstruction due to satellites. 
Table 4 Review: laparoscopic approach [8, 20-25]

\begin{tabular}{|c|c|c|c|c|c|c|c|c|}
\hline & \multicolumn{8}{|l|}{ Author } \\
\hline & \multicolumn{2}{|c|}{ Hernandez [23] } & \multirow[t]{2}{*}{ Meyer [22] } & \multirow[t]{2}{*}{ Palanivelu [8] } & \multirow[t]{2}{*}{ Levy [24] } & \multirow[t]{2}{*}{ Klem [25] } & \multirow[t]{2}{*}{ Kanetaka [20] } & \multirow[t]{2}{*}{ Nirasawa [21] } \\
\hline & Case 1 & Case 2 & & & & & & \\
\hline Location & $\begin{array}{l}\text { Stomach- } \\
\text { Duodenum }\end{array}$ & Stomach & Stomach & Stomach & Stomach & $\begin{array}{l}\text { Small } \\
\text { Intestine }\end{array}$ & $\begin{array}{l}\text { Stomach- } \\
\text { Duodenum }\end{array}$ & $\begin{array}{l}\text { Stomach- } \\
\text { Duodenum }\end{array}$ \\
\hline Size & $?$ & $?$ & Diameter: $11 \mathrm{~cm}$ & $?$ & $4,500 \mathrm{~g}$ & $?$ & $100 \mathrm{~g}$ & $11 \times 9 \times 6 \mathrm{~cm}$ \\
\hline Associated pathology & None & None & None & Satellites & None & Satellites & None & None \\
\hline Time of operation (min) & 180 & 210 & 180 & & & & 120 & 300 \\
\hline $\begin{array}{l}\text { Extension of initial } \\
\text { port wound }\end{array}$ & No & No & Yes & Yes & & & No & Yes \\
\hline Additional therapy & None & None & None & None & None & None & $\begin{array}{l}\text { Endoscopic } \\
\text { removal of } \\
\text { fragments }\end{array}$ & None \\
\hline Conversion to laparotomy & No & No & No & No & Yes & Yes & No & No \\
\hline
\end{tabular}

With laparoscopy this procedure is far more challenging. The risk of spilling contaminated hair fragments into the abdominal cavity makes the laparoscopic approach even less attractive. In addition, due to the rarity of trichobezoars, the technique of laparoscopic removal and inspection of the entire intestine may be hard to acquire. The benefits of laparoscopic removal of trichobezoars with intestinal obstruction have been reported to have better cosmetic result, less postoperative complications and reduced admittance time [39]. Not all authors, however, mention the length of hospital stay. Although several reports stress the excellent cosmetic result of the laparoscopic approach, they also report the frequent need to extend the initial port wounds, sometimes with up to 2-4 cm [8, 21, 22].

\section{Laparotomy}

Laparotomy was successful in all of our cases, although minor wound infection occurred in two patients. We identified 100 cases in the literature who underwent conventional laparotomy; all were successful. Twelve patients (12\%) suffered from one or more complications (Table 3). Perforation of the intestine during removal of the trichobezoar was reported in three patients [40-42], minor wound infection in three $[11,29,43]$, pneumonia in two [44, 45], paralytic ileus in two [46, 47], ileal trichobezoar in one and fecal leakage through the lower part of the laparotomy wound in one patient $[10,48]$. Due to $100 \%$ success rate, the relatively low complication rate, the low complexity, and the ability to carefully examine the entire gastrointestinal tract for satellites in a short period of time, laparotomy is still considered the treatment of choice in our center.

\section{Rapunzel syndrome}

In Rapunzel syndrome, we see no other valid option than conventional laparotomy. In our patient (\#1) endoscopy was tried, but proved unsuccessful. At laparotomy the trichobezoar was removed without postoperative complications. Actually, endoscopic removal should not even be tried as the tail usually reaches into the jejunum and manipulation carries the risk of parts breaking off, which cannot be removed endoscopically [8-10]. Laparoscopy was successful incidentally in trichobezoars extending into the duodenum, but as most authors would agree that the Rapunzel tail has at least to reach into jejunum, these cases did not meet the criteria for Rapunzel syndrome [6, 7, 20,21,23]. The removal of the tail requires careful manipulation of the bowel to prevent perforation; sometimes multiple enterotomies are needed. It is practically impossible to safely obtain complete removal of the trichobezoar in Rapunzel syndrome.

In conclusion, trichobezoar should be considered in young females presenting with non-specific abdominal complaints. Endoscopy can be used as a diagnostic modality for these patients as it can differentiate trichobezoar from other types of bezoars, which can be removed safely with endoscopy. As far as treatment is concerned, however, we consider conventional laparotomy to be the treatment of choice in children with trichobezoar and to be the only valid treatment in children with Rapunzel syndrome. The literature provides no evidence of superiority of endoscopy or laparoscopy. The lack of invasiveness of these techniques does not seem to outweigh the disadvantages and the complexity of these procedures. In addition to the acute surgical treatment, psychiatric consultation is necessary in order to prevent relapses. 
Conflict of interest statement The authors declare that they have no conflict of interest.

Open Access This article is distributed under the terms of the Creative Commons Attribution Noncommercial License which permits any noncommercial use, distribution, and reproduction in any medium, provided the original author(s) and source are credited.

\section{References}

1. Diefenbach GJ, Reitman D, Williamson DA (2000) Trichotillomania: a challenge to research and practice. Clin Psychol Rev 20:289-309

2. Carr JR, Sholevar EH, Baron DA (2006) Trichotillomania and trichobezoar: a clinical practice insight with report of illustrative case. J Am Osteopath Assoc 106:647-652

3. Bouwer C, Stein DJ (1998) Trichobezoars in trichotillomania: case report and literature review. Psychosom Med 73:653-656

4. Sehgal VN, Srivastava G (2006) Trichotillomania \pm trichobezoar: revisited. J Eur Acad Dermatol Venereol 20:911-915

5. Debakey M, Oschner A (1939) Bezoars and concretions, comprehensive review of literature with analysis of 303 collected cases and presentation of 8 additional cases. Surgery 5:132-160

6. Vaughan ED Jr, Sawyers JL, Scott HW Jr (1968) The Rapunzel syndrome. An unusual complication of intestinal bezoar. Surgery 63:339-343

7. Naik S, Gupta V, Rangole A, Chaudhary AK, Jain P, Sharma AK (2007) Rapunzel syndrome reviewed and redefined. Dig Surg 24:157-161

8. Palanivelu C, Rangarajan M, Senthilkumar R, Madankumar MV (2007) Trichobezoars in the stomach and ileum and their laparoscopy-assisted removal: a bizarre case. Singapore Med J 48:37-39

9. Khattak S, Kamal A (2004) Trichobezoar. Gomal J Med Sci 2:25-26

10. Hoover K, Piotrowski J, Pierre K, Katz A, Goldstein AM (2006) Simultaneous gastric and small intestinal trichobezoars-a hairy problem. J Pediatr Surg 41:1495-1497

11. Armstrong JH, Holtzmuller KC, Barcia PJ (2001) Gastric trichobezoar as a manifestation of child abuse. Curr Surg 58:202-204

12. Cohen LJ, Stein DJ, Simeon D, Spadaccini E, Rosen J, Aronowitz B et al (1995) Clinical profile, comorbidity and treatment history in 123 hairpullers: a survey study. J Clin Psychiatr 56:319-326

13. Ventura DE, Herbella FAM, Schettini ST, Delmonte C (2005) Rapunzel syndrome with a fatal outcome in a neglected child. J Pediatr Surg 40:1665-1667

14. Mehta MH, Patel RV (1992) Intussusception and intestinal perforations caused by multiple trichobezoars. J Pediatr Surg 27:1234-1235

15. Schreiber H, Filston HC (1976) Obstructive jaundice due to gastric trichobezoar. J Pediatr Surg 11:103-104

16. Hossenbocus A, Colin-Jones DG (1973) Trichobezoar, gastric polyposis, protein losing enteropathy and steatorhoea. Gut 14:130-132

17. Shawis RN, Doig CM (1984) Gastric trichobezoar with transient pancreatitis. Arch Dis Child 59:994-995

18. Michail S, Nanagas V, Mezoff AG (2008) An unusual cause of postfundoplication vomiting. J Pediatr Surg 43:E45-E47

19. Wang YG, Seitz U, Li ZL, Soehendra N, Qiao XA (1998) Endoscopic management of huge bezoars. Endoscopy 30:371374

20. Kanetaka K, Azuma T, Ito S, Matsuo S, Yamaguchi S, Shirono K et al (2003) Two-channel method for retrieval of gastric trichobezoar: report of a case. J Pediatr Surg 38:1-2
21. Nirasawa Y, Mori T, Ito Y, Tanak H, Seki N, Atomi Y (1998) Laparoscopic removal of a large gastric trichobezoar. J Pediatr Surg 33:663-665

22. Meyer-Rochow GY, Grunewald B (2007) Laparoscopic removal of a gastric trichobezoar in a pregnant woman. Surg Laparosc Endosc Percutan Tech 17:129-132

23. Hernandez-Peredo-Rezk G, Escarcega-Fujigaki P, CampilloOjeda Z, Sanchez-Martinez ME, Rodriguez-Santibanez MA, del Angel-Aguilar A et al (2009) Trichobezoar can be treated laparoscopically. J Laparoendoscop Adv Surg Tech A 19:111-113

24. Levy RM, Komanduri S (2007) Images in clinical medicine. Trichobezoar. N Engl J Med 357:e23

25. Klem TMAL, Stockmann HBAC, Mattens ECJL, Ruseler CH (2005) Een patiënte met een trichobezoar. Ned Tijdschr Heelkd 14:19-21

26. Alsafwah S, Alzein M (2000) Small bowel obstruction due to trichobezoar: role of upper endoscopy in diagnosis. Gastrointest Endosc 52:784-786

27. De Backer A, Van Nooten V, Vandenplas Y (1999) Huge gastric trichobezoar in a 10 year old girl: case report with emphasis on endoscopy in diagnosis and therapy. J Pediatr Gastroenterol Nutr 28:513-515

28. Stein-Wexler R, Wooten-Gorges SL, Shakibai S, Graf J, Miller SM, Taylor D et al (2006) Trichobezoar: an unusual cause for pancreatitis in a patient with sickle cell anemia. Clin Adv Hematol Oncol 4:471-473

29. Duncan ND, Aitken R, Venugopal S, West W, Carpenter R (1994) The Rapunzel syndrome: report of a case and review of the literature. West Indian Med J 43:63-65

30. Koulas SG, Zikos N, Charalampous C, Christodoulo K, Sakkas L, Katsamakis N (2008) Management of gastrointestinal bezoars: an analysis of 23 cases. Int Surg 93:95-98

31. Jensen AR, Trankiem CT, Lebovitch S, Grewal H (2005) Gastric outlet obstruction secondary to a large trichobezoar. J Pediatr Surg 40:1364-1365

32. Coulter R, Anthony MT, Bhuta P, Memon MA (2005) Large gastric trichobezoar in a normal healthy woman: case report and review of pertinent literature. South Med J 98:1042-1044

33. Saeed ZA, Ramirez FC, Hepps KS et al (1993) A method for the endoscopic retrieval of trichobezoars. Gastrointest Endosc 39:698-700

34. Van Gossum A, Delhaye M, Cremer M (1989) Failure of non surgical procedures to treat gastric trichobezoar. Endoscopy 21:113

35. Soehendra N (1989) Endoscopic removal of a trichobezoar. Endoscopy 211:201

36. Dumonceaux A, Michaud L, Bonnevalle M, Debeugny P, Gottrrand F, Turck D (1998) Trichobezoars in children and adolescents. Arch Pediatr 5:996-999

37. Diettrich NA, Gau FC (1985) Postgastrectomy phytobezoarendoscopic diagnosis and treatment. Arch Surg 120:432-435

38. Gaia E, Gallo M, Caronna S, Angeli A (1998) Endoscopic diagnosis and treatment of gastric bezoars. Gastrointest Endosc 48:113-114

39. Yau KK, Siu WT, Law BK, Cheung HY, Ha JP, Li MK (2005) Laparoscopic approach compared with conventional open approach for bezoar induced small bowel obstruction. Arch Surg 140:972-975

40. Memon SA, Mandhan P, Queshi JN, Shairani AJ (2003) Recurrent Rapunzel syndrome: a case report. Med Sci Monit 19:343347

41. Singla SL, Rattan KN, Kaushik N, Pandit SK (1999) Rapunzel syndrome - a case report. Am J Gastroenterol 94:1970-1971

42. Perera BJ, Romanie Rodrigo BK, de Silva TU, Ragunathan IR (2005) A case of trichobezoar. Ceylon Med J 50:168-169 
43. Larsson LT, Nivenius K, Wettrell G (2004) Trichobezoar in a child with concomitant coeliac disease: a case report. Acta Pediatr 93:278-280

44. Philips MR, Zaneer S, Drugas GT (1998) Gastric trichobezoar: case report and literature review. Mayo Clin Proc 73:653-656

45. Sharma V, Sharma ID (1990) Unusual presentation of trichobezoar. Indian Pediatr 27:157-159
46. Zent RM, Cothren CC, Moore EE (2004) Gastric trichobezoar and Rapunzel syndrome. J Am Coll Surg 199:990

47. Weiss M, Danoff DM, Wood BP (1998) Radiological case of the month. Jejunojejunal intussusception caused by a trichobezoar with a tail. Arch Pediatr Adolesc Med 152:403-404

48. Varma A, Sudhindra BK (1998) Trichobezoar with small bowel obstruction. Indian J Pediatr 65:761-763 